\title{
Molecular analysis of the recF gene of Escherichia coli
}

(nucleotide sequence/genetic recombination/DNA repair/DNA synthesis/maxicells)

\author{
Michael A. Blanar, Steven J. Sandler, Maria-Eugenia Armengod*, Lloyd W. Ream ${ }^{\dagger}$, \\ and Alvin J. Clark
}

Department of Molecular Biology, University of California, Berkeley, CA 94720

Communicated by Franklin W. Stahl, March 13, 1984

\begin{abstract}
We analyzed the nucleotide sequence of a 1.325-kilobase region of wild-type Escherichia coli containing a functional $\operatorname{rec} F$ gene and six $\mathrm{Tn} 3$ mutations that inactivate $r e c F$. The analysis shows a potentially translatable reading frame of 1071 nucleotides, which is interrupted by all six insertions. A protein of $\mathbf{4 0 . 5}$ kilodaltons would result from translation of the open reading frame, and a radioactive band of protein of an apparent molecular weight of $\approx 40$ kilodaltons was seen by the maxicell method using a recF ${ }^{+}$plasmid. Putative truncated peptides were seen when two recF::Tn3 mutant plasmids were used. Differential expression of $\operatorname{dnaN}$ and $\mathrm{recF}$ from a common promoter was noted. recF 332:: Tn3 was transferred to the chromosome where, in hemizygous condition, it produced UV sensitivity indistinguishable from that produced by two presumed recF point mutations.
\end{abstract}

The recF gene of Escherichia coli lies within a cluster of genes involved in DNA metabolism, the gene order being gyrB recF dnaN dnaA (1). gyrB has been shown to code for one of the subunits of DNA gyrase (2), dnaN determines the $\beta$ subunit of DNA polymerase III holoenzyme (3), and $d n a A$ encodes a 52 -kilodalton $(\mathrm{kDa})$ protein $(4,5)$ involved with the initiation of replication of the Escherichia coli chromosome (6).

The phenotype of a $r e c F$ mutant indicates that $r e c F$ also is involved in DNA metabolism and possibly with replication. UV irradiation of recF143 mutants produces a wide variety of effects (e.g., refs. 7-9) economically interpretable by the hypothesis that induction of the lexA regulon is partially inhibited (10). Such induction is thought to depend in part on formation of single-strand gaps because of incomplete replication of UV-damaged DNA and in part on association of $\operatorname{rec} A$, lex $A$, and $c I$ gene products with these gaps (11). Therefore, it is plausible that the $r e c F$ gene product is involved in some way with formation of these gaps or association of single-stranded DNA with proteins. recF143 strains also behave abnormally when exposed to treatments by other DNA-damaging agents [e.g., psoralen and visible light (12), thymine starvation (unpublished results), nalidixic acid (7, 13), and coumermycin (14)], leading one to the hypothesis that $\mathrm{recF}^{+}$genotype is required for normal SOS inducibility (15).

Recently, evidence has appeared that recF143 substantially inhibits a variety of DNA metabolic events in unirradiated cells: plasmid recombination $(16,17)$ and one type of mismatch correction (ref. 18; unpublished results). recF143 also substantially reduces conjugational recombination $(7,14,19)$ and $\lambda$ phage-prophage recombination (20) in special mutant backgrounds. These effects are plausibly explained by hypothesizing that $r e c F$ encodes an endonuclease (21) or a protein involved in DNA synthesis. Cloning of the $r e c F$ region

The publication costs of this article were defrayed in part by page charge payment. This article must therefore be hereby marked "advertisement" in accordance with 18 U.S.C. $\$ 1734$ solely to indicate this fact. has been described (22), and in this paper we identify the recF gene product.

\section{MATERIALS AND METHODS}

Bacterial Strains. All bacterial strains used are derivatives of $E$. coli $\mathrm{K}-12$. Gene symbols are those used by Bachmann (23). JC11033 was produced by transforming the Hfr strain JC158 (24) with the plasmid pML2.

Plasmids. pJC605 is a 7.9-kilobase (kb) plasmid derived by cloning a 3.6-kb fragment carrying $r e c F$, called $\mathrm{cJC} 1$, with pBR322 (22). pMAB4 is a 3.6-kb plasmid derived by cloning the 1.3-kb EcoRI-Pvu II recF ${ }^{+}$fragment of $\mathrm{cJC1}$ into the 2.3-kb EcoRI-Pvu II $b^{+} a^{+}$fragment of pBR322. pJC655 is a 7.7-kb de(bla)300 ampicillin-sensitive $\left(\mathrm{Amp}^{\mathrm{S}}\right)$ deletion mutant derivative of pJC605 (22). Tn3 mutant derivatives of pJC655 $(12.7 \mathrm{~kb})$ were isolated by conduction with the conjugative plasmid pJC753. pJC753 is a Tn3 insertion mutant of $\mathrm{R} 1$ drd-19.K1, a plasmid that has lost $\mathrm{Tn} 3$ and $\mathrm{Tn} 4$ by deletion and was produced upon transposition of $\mathrm{Tn} 3$ from pJC752, a pSC101::Tn3 derivative (unpublished results). pML2 is a $13.5-\mathrm{kb}$ plasmid containing a 6.7-kb EcoRI aphA ${ }^{+}$ fragment cloned into ColE1 (25). Construction of pSJS9, pSJS40, pSJS76, and pSJS77 using the temperature-dependent runaway-copy vector pBEU28 (26) will be published elsewhere.

Media, Materials, and Mutagenesis. Media, materials, and some methods have been described or cited by Ream and Clark (22). To detect transposon mutagenesis, JC13225, a strain carrying the target plasmid pJC655 and the conjugative plasmid pJC753 was used as donor, and JC9239 (recF143) was used as recipient in a $1-\mathrm{hr}$ conjugation at $37^{\circ} \mathrm{C}$. Colonies of $\mathrm{Amp}^{\mathrm{R}} \mathrm{Tet}^{\mathrm{R}}$ (Amp- and tetracycline-resistant) $\left[\mathrm{Met}^{+} \mathrm{Trp}^{+}\right.$ $\mathrm{Ile}^{+} \mathrm{Val}^{+}$] transconjugants appeared at frequencies of $3 \times$ $10^{-8}$ and $1 \times 10^{-7}$ per donor in two experiments while the conjugative plasmid was transmitted at $3 \times 10^{-5}$ and $1 \times$ $10^{-3}$, respectively. Six $\mathrm{UV}^{\mathrm{s}}$ transconjugants were found among 159 tested, indicating that the plasmid-borne $r e c F$ gene was mutant. Hydroxylamine $\left(\mathrm{H}_{2} \mathrm{NOH}\right)$ mutagenesis of plasmid DNA was performed in vitro as described by Humphreys et al. (27). Plasmid DNA (5 $\mu \mathrm{g})$ was incubated with 1 $\mathrm{M} \mathrm{H}_{2} \mathrm{NOH}$ (in $1 \mathrm{mM}$ EDTA) at $72^{\circ} \mathrm{C}$ for $30 \mathrm{~min}$ in one experiment and at $60^{\circ} \mathrm{C}$ for $15 \mathrm{~min}$ in another.

Sequence Determination. Sequencing was done essentially by the procedure of Maxam and Gilbert (28). 5' termini were labeled with $\left[\gamma^{32} \mathrm{P}\right]$ ATP (Amersham; $>5000 \mathrm{Ci} / \mathrm{mmol} ; 1 \mathrm{Ci}$ $=37 \mathrm{GBq}$ ) and polynucleotide kinase (P-L Biochemicals). $3^{\prime}$ ends were labeled with the large fragment of DNA polymer-

Abbreviations: Amp, ampicillin; Tet, tetracycline; Str, streptomycin; Kan, kanamycin; superscripts $R, S$, +, and -, resistant/resistance, sensitive/sensitivity, independent/independence, and dependent/dependence; $k b$, kilobase(s).

*Present address: Instituto de Investigaciones Citologicas, Amadeo de Saboya 4, Valencia-10, Spain.

tPresent address: Department of Biology, Indiana University, Bloomington, IN 47405. 
ase (Klenow; Boehringer Mannheim) and $\alpha-{ }^{32} \mathrm{P}$-labeled deoxyribonucleoside triphosphates (Amersham; $>3000 \mathrm{Ci}$ / mmol).

Maxicells. Labeling with L- $\left[{ }^{35}\right.$ S $]$ methionine (Amersham; $\approx 1200 \mathrm{Ci} / \mathrm{mmol}$ ) was performed essentially as described by Sancar et al. (29). Labeling was done at $42^{\circ} \mathrm{C}$ for $1 \mathrm{hr}$.

\section{RESULTS}

Tn3 and Hydroxylamine-Induced Mutations. In order to ascertain the limits of the $r e c F$ gene, we generated and characterized six insertion mutations of $\operatorname{Tn} 3$ in the cloned recF gene. All the insertions resulted in the inability of the plasmid-borne $\operatorname{recF}$ gene to confer $\mathrm{UV}^{\mathrm{R}}$ to an otherwise $\mathrm{UV}^{\mathrm{S}}$ recF143 chromosomal mutant strain. Each of the resultant plasmids complemented the temperature-sensitive mutation dnaN608 (data not shown), indicating that none of these Tn3 insertions eliminated dnaN function. Restriction enzyme mapping with BamHI and HincII (30) was used to locate roughly and orient the transposon in each mutant insertion (data not shown). The six insertions occurred within a region of about 950 base pairs. Exact positions as determined by nucleotide sequencing are indicated in Fig. 1. As delimited by these $\mathrm{Tn} 3$ insertion mutations, the $r e c F$ gene and any other DNA fragment necessary for expression must extend from at least position 41 to position 983 in Fig. 1 .

In addition to the $\mathrm{Tn} 3$ insertion mutations, we also generated a nonconditional, $\mathrm{H}_{2} \mathrm{NOH}$-induced $\mathrm{recF}$ mutation, recF289. We transformed a sup ${ }^{+}$recF143 strain, JC11810, with $\mathrm{H}_{2} \mathrm{NOH}$-treated DNA of pJC605 and selected for Tet ${ }^{\mathrm{R}}$. The resultant transformants were screened for sensitivity to $3.5 \mu \mathrm{g}$ of nitrofurantoin per $\mathrm{ml}$ at $30^{\circ} \mathrm{C}$ and $42^{\circ} \mathrm{C}$. Of 4500 transformants screened, 7 highly sensitive transformants were identified, and 1 of these, nitrofurantoin-sensitive at both temperatures, was found to contain a plasmid whose recF mutation could not be suppressed by various nonsense suppressors. This plasmid, pJC610, carries recF289 and complements dnaN608 (data not shown), demonstrating that it is $\operatorname{dnaN^{+}}$.

Translocation of Plasmid-Carried recF Mutation. The plasmid-borne $r e c F$ mutations were all detected in heterozygous condition with the chromosomal mutation recF143. To produce cells hemizygous for these mutations, we did the following: (i) transformed a $r e c F^{+}$dnaA508 $\left(42^{\circ} \mathrm{C}^{\mathrm{S}}\right)$ strain with the appropriate plasmid; (ii) selected and purified two spontaneous $42^{\circ} \mathrm{C}^{\mathrm{R}}$ mutants of the resultant transformants to obtain plasmids that had integrated by homologous recombination in the $r e c F$ region; (iii) incubated an inoculum from each clone at $30^{\circ} \mathrm{C}$ in the absence of antibiotics for $24 \mathrm{hr}$, followed by subculturing at $30^{\circ} \mathrm{C}$ for an additional $24 \mathrm{hr}$ before screening individual clones for $42^{\circ} \mathrm{C}^{\mathrm{S}}$ and for $\mathrm{UV}^{\mathrm{S}}$, to detect plasmid excision and either a hemizygous or homozygous recF mutation; and (iv) used the resultant isolates as donors in P1 transduction of the nearby tnaA300::Tn10 marker, selecting $\mathrm{Tet}^{\mathrm{R}} 42^{\circ} \mathrm{C}^{\mathrm{R}}$ transductants and screening for $\mathrm{UV}^{\mathrm{S}}$, to isolate those that inherited the recipient's $\mathrm{dnaA}^{+}$and the donor's recF mutant allele. In steps $i i i$ and $i v$, we were able to isolate respectively $d n a A 508$ and $d n a A^{+}$strains that were hemizygous for recF289 and recF332::Tn3. Translocation was verified for the latter mutation by the Southern transfer method (31) using EcoRI digests of chromosomal DNA and pJC605 DNA as a labeled probe (data not shown). Strains hemizygous for recF289 and recF332::Tn3 were found to be as $U V^{\mathrm{S}}$ as the hemizygous recF143 strain, JC11803 (data not shown). When crossed with donor JC11033, each produced essentially the same frequency of $\mathrm{Thr}^{+} \mathrm{Leu}^{+}\left[\mathrm{Str}^{\mathrm{R}}\right.$ (streptomycinresistant) $\mathrm{Ser}^{+}$] and $\mathrm{Kan}^{\mathrm{R}}$ (kanamycin-resistant) [ $\mathrm{Str}^{\mathrm{R}} \mathrm{Ser}^{+}$] transconjugants as $\mathrm{JC} 11803$, both with chromosomal and plasmid pML2 markers, respectively (data not shown).

As the recF::Tn3 mutations had been detected by their failure to complement recF143, we tested their ability to complement recF289. Strains carrying plasmids with the Tn 3 insertions at the extremes of the $r e c F$ region and with recF289 on the chromosome were $\mathrm{UV}^{\mathrm{S}}$, whereas those with recF $F^{+}$on the chromosome were $\mathrm{UV}^{\mathrm{R}}$.

DNA Sequence Analysis of the recF Gene. The nucleotide sequence of a $1.325-\mathrm{kb}$ Msp I-EcoRI fragment, which has been shown to contain a completely functional recF gene (ref. 22; unpublished results) is presented in Fig. 1. It includes two long open reading frames. The shorter consists of 210 nucleotides and begins at the $M s p$ I sequence. It encodes the carboxyl-terminal 70 amino acids of dnaN protein (32) and ends at a TAA that overlaps, by one nucleotide, the first ATG of the longer open reading frame. Beginning at this ATG, the latter consists of 1071 nucleotides, which could encode a 357-amino-acid protein of 40,519 daltons. The sequence A-A-T-G-A-G is centered 9 nucleotides prior to the $A$ of the first ATG. Five of the 6 nucleotides of this sequence (underlined) are complementary with the $3^{\prime}$ end of $E$. coli 16S rRNA. Since the average ribosome-binding site has a 4.8-nucleotide complementarity centered 9.8 nucleotides from the A of an initiating ATG $(33,34)$, we hypothesize that the A-A-T-G-A-G sequence is a suitable ribosome-binding sequence. Thus, the longer open reading frame is potentially translatable and may be $r e c F$.

Maxicell Analysis of the recF Protein. We transformed pSJS9, pSJS40, pSJS76, and pSJS77 into an appropriate $\mathrm{UV}^{\mathrm{S}}$ recF143 recipient mutant strain and screened the $\mathrm{Kan}^{\mathrm{R}}$ transformants for $r e c F^{+}$complementation. The strains harboring pSJS9 and pSJS40 yielded $\mathrm{UV}^{\mathrm{R}}$ colonies at $30^{\circ} \mathrm{C}$, whereas those containing pSJS76 and pSJS77 remained UV $\mathrm{UV}^{\mathrm{s}}$ (data not shown).

Using $\left[{ }^{35} \mathrm{~S}\right]$ methionine-labeled extracts from maxicells carrying these four plasmids, we obtained the autoradiograms shown in Fig. $2 b$. Temperature induction of pSJS9 $\left(\mathrm{recF}^{+}\right)$for $1 \mathrm{hr}$ results in the expression of four proteins with molecular masses of $59,47,43$, and $29 \mathrm{kDa}$. Identities of these proteins have been confirmed by deletion analysis, and this evidence will be presented elsewhere. The 59-kDa protein is the result of a fusion of 93 codons of $\lambda$ phage exo (35) with 446 codons of dnaA (36). The $47-\mathrm{kDa}$ protein has not been identified, but it seems to be vector-encoded. The 43and $29-\mathrm{kDa}$ proteins are the dnaN and $\lambda$ phage bet gene products, respectively (35). $\lambda$ phage $N$ protein was not observed in these experiments. It is of interest to note that all genes downstream of the temperature-induced $p L$ and $p R$ promoters produce substantial amounts of proteins, but that the $r e c F$ gene product is not observed. We were successful in identifying the $r e c F$ gene product only upon construction of deletion derivatives of pSJS9.

From the DNA sequence analysis, we expected pSJS40 $\left(\mathrm{recF}^{+}\right)$to encode proteins of 7.2 and $43 \mathrm{kDa}$ in addition to the $40.5-\mathrm{kDa}$ recF protein. The smaller protein would result from a fusion of the 55 amino-terminal codons of $\lambda$ phage $N$ (35) to the 10 carboxyl-terminal codons of dnaN and would not be seen under the conditions we used. The larger protein would result from translation initiating at an ATG in the $\lambda$ phage $N$ gene, 23 codons upstream of the recF initiating codon. As shown in Fig. $2 b$, we observed two proteins of approximately the expected weights upon incubation at $42^{\circ} \mathrm{C}$ to initiate transcription from $p L$ and $p R$. With the $\mathrm{Tn} 3$ mutant plasmid pSJ76, we saw neither the $42-$ nor $40-\mathrm{kDa}$ bands. Instead a new band appeared at $20.5 \mathrm{kDa}$. This is the size expected of the product of fusion between $\mathrm{recF}$ and the codons of $\operatorname{Tn} 3$ in the appropriate reading frame. A larger peptide $(24 \mathrm{kDa})$ with the additional 23 amino acids is probably obscured by the heavily labeled $c I$ and aphA gene products. With plasmid pSJS77, we saw proteins of apparent molecular masses $36 \mathrm{kDa}$ and $40 \mathrm{kDa}$ as expected from the recF and upstream initiation codons, respectively. 
-179 GTT ACC TAT AGC GGT GCG GAG ATG GAA ATC GGC TTC AAC GTC AGT TAT GTG CTG GAT GTT CTG AAC GCG CTG AAA Val Thr Tyr Ser Gly Ala Glu Met Glu Ile Gly Phe Asn Val Ser Tyr Val Leu Asp Val Leu Asn Ala Leu Lys Hinf I

-104 TGC GAA AAC GTC CGC ATG ATG CTG ACC GAT TCG GTT TCC AGC GTG CAG ATT GAA GAT GCG GCC AGC CAG AGC GCG Cys Glu Asn Val Arg Met Met Leu Thr Asp Ser Val Ser Ser Val Gln Me Glu Asp Ala Ala Ser Gln Ser Ala

-29 GCT TAT GTT GTC ATG CCA ATG AGA CTG Set Leu Thr Arg Leu Leu Ile Arg Asp Phe Arg A8n Ile Glu Ala Tyr Val Val Met Pro Met Arg Leu ***

recF334: : $\operatorname{Tn} 3$ Thr Ala Asp Leu Ala Leu Ser Pro Gly Phe Aen the Leu Val Gly Ala Asn Gly Ser Gly Lys Thr Ser Val Leu Thr Ala Asp Leu Ala Leu Ser Pro Gly Phe Asn the Leu Val Gly Ala Asn Gly Ser Gly Lys Thr Ser Val Leu Thr Ala Asp Leu Ala Leu Ser Pro Gly Phe ABn the Leu Val Gly Ala Asn Gly Ser Gly Lys Thr Ser Val Leu ACC GCG GAT CTC GCC TTA TCT CCC GGC TTT AAC TTT CTG GTA GGT GCC AAC GGC AGT GGC AAA ACC AGC GTG CTG recF332: : $\operatorname{Tn} 3$

Glu Ala Tle Tyr thr Leu Gly His Gly Arg Ala the Arg Ser Leu Gln The Gly Arg Val Mle Arg His Glu Gln GAA GCC ATC TAT ACG CTC GGC CAT GGT CGG GCG TTT OGC AGT TTG CAG ATT GGT OGC GTC ATT OGC CAT GAG CAG Glu Ala Phe Val Leu His Gly Arg Leu Gln Gly Glu Glu Arg Glu Thr Ala Tle Gly Leu Thr Lys Asp Lys Gln GAg GCG TTT GTT CTC CAC GGg CGA TTA CAg GGC GAN GAg OGC GAg ACA GCG ATT GGC TTA ACC aAM GAC AAA CAG

Gly Asp Ser Lys Val Arg Ile Asp Gly ${ }^{100}$ Thr Asp Gly His Lye Val Ala Glu Leu Ala His Leu Met Pro Met Gln

Gly Asp Ser Lys Val arg Tle Asp Gly Ihr Asp Gly His Lys Val Ala Glu Leu Ala His Leu Met Pro Met Gln GGC GAC AGC MA GTC OGC ATC GAC GGT ACA GAC GGG CAT MG GTC GCG GM CTG GCG CAC CTG ATG CCA ATG CAG 120 Leu Ile Thr Pro Glu Gly Phe Thr Leu Leu ABn Gly Gly Pro Lys Tyr Arg Arg Ala Phe Leu Asp Trp Gly Cys TTG ATA ACG CCA GAA GGG TTT ACT TTA CTC MAC GGC GGC CCC NM TAC AGA NGA GCA TTC CTC GAC TGG GGA TGC 150

160

Phe His Asn Glu Pro Gly Phe Phe Thr Ala Trp Ser ABn Leu Lys Arg Leu Leu Lys Gln Arg Asn Ala Ala Leu TTT CAC AAC GAA CCC GGA TTT TTC ACC GCC TGG AGC MAT CTC MAG CGA TTG CTC AAG CAG OGC AAT GCG GCG CTC

180

Arg Gln Val Thr Arg Tyr Gln Gln Leu Arg Pro Tro Asp Lys Glu Leu Ile Pro Leu Ala Glu Gln Ile Ser 190 CGC CAG GTG ACA CGT TAC GAA CAG CTA OGC OCG TGG GAT AAA GAG CTG ATC CCG CTG GCG GAG CAA ATC AGC ACC

Trp Arg Ala Glu Tyr Ser Ala Gly Tle Ala Ala Asp Met Ala Asp Thr Cys Lys Gln Phe Leu Pro Glu Phe Ser TGG OGC GCG GAG TAT AGC GCC GGT ATC GCG GCC GAT ATG GCT GAT ACC TGT NAG CA TTT CTC CCT GAG TTT TCT Leu Thr Phe Ser Phe Gln Arg Gly Tro Glu Lys Glu Thr Glu 230 Ala Glu Val Leu Glu Arg Asn Phe GLu Arg CTG ACT TTC TCT TTC CAg OGC GGC TGG GAG NAA GAG ACA GA TAT GCT GAG GTG CTG GAA OGT AAT TTT GAA CGC

$250 \quad 260$

Asp Arg Gln Leu Thr Tyr Thr Ala His Gly Pro His Lys Ala Asp Leu Arg Tle Arg Ala Asp Gly Ala Pro Val GAT CGC CAG CTA ACC TAC ACC GCG CAC GGC CCG CAC ANA GCG GAC TTA CGC ATT OGC GCC GAC GGT GCG CCG GTG

270280 Glu Asp Thr Leu Ser Arg Gly Gln Leu Lys Leu Leu Met Cys Ala Leu Arg Leu Ala Gln Gly Glu Phe Leu Thr GAA GAT ACC TTA TCG OGT GGG CAG CTT AAG CTG TTG ATG TGC GCC TTA OGT CTG GCG CAA GGA GAG TTC CTC ACC CGT GA AGC GGG CGG OGG TGT CTC TAC CTG ATA GAT GAT TTT GCC TCT GAG CTT GAT GAT GAG OGT OGC GGG CTG recR336 : : $\operatorname{Tn} 3$ 320 330 340 Leu Ala Ser Arg Leu Lys Ala Thr Gln Ser Gln Val Phe Val Ser Ala Ile Ser Ala Glu His Val Ile Asp Met CTT GCC AGC OGC TTA AAA GCG ACG CAA TCA CAG GTC TTT GTC AGC GCG ATC AGT GCT GAA CAC GTT ATA GAC ATG recF333 : : Tn3 350

Ser Asp Glu Asn Ser Lys Met Phe Thr Val Glu Lys Gly Lys The Thr Asp *** TCG GAC GAA AAT TCG AAG ATG TTT ACC GTG GAA AAG GGT AAA ATA ACG GAT TAA CCCAAGTATAAATGAGCGAGAaACGTT

Fig. 1. DNA sequence of the $r e c F$ gene and adjacent regions. The $r e c F$ gene and the deduced amino acid sequence begin at position +1 and extend to the TAA termination codon at position 1074. The carboxyl-terminal sequence of dnaN extends from position -212 to +1 , and the amino terminus of the gyrB gene begins at position 1103. Restriction endonuclease recognition sequences are underlined. Positions of insertion of the six $\mathrm{Tn} 3$ mutations. Tn3 elements were found in both orientations. In recF334 and recF336, Tn3 is oriented so that the bla gene is proximal to the $g y r B$ side of $r e c F$, whereas bla is distal to the $g y r B$ side in the insertion mutations recF332, recF333, recF335, and recF337. Description of the sequencing strategy is available upon request. 
(a)

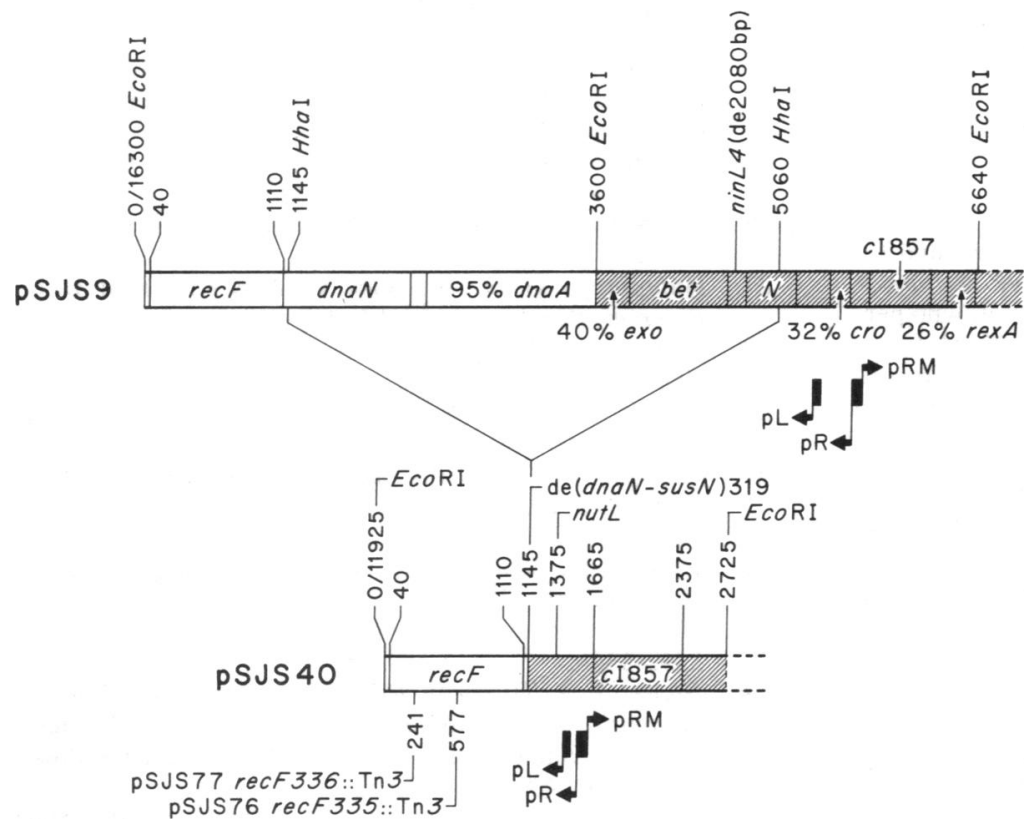

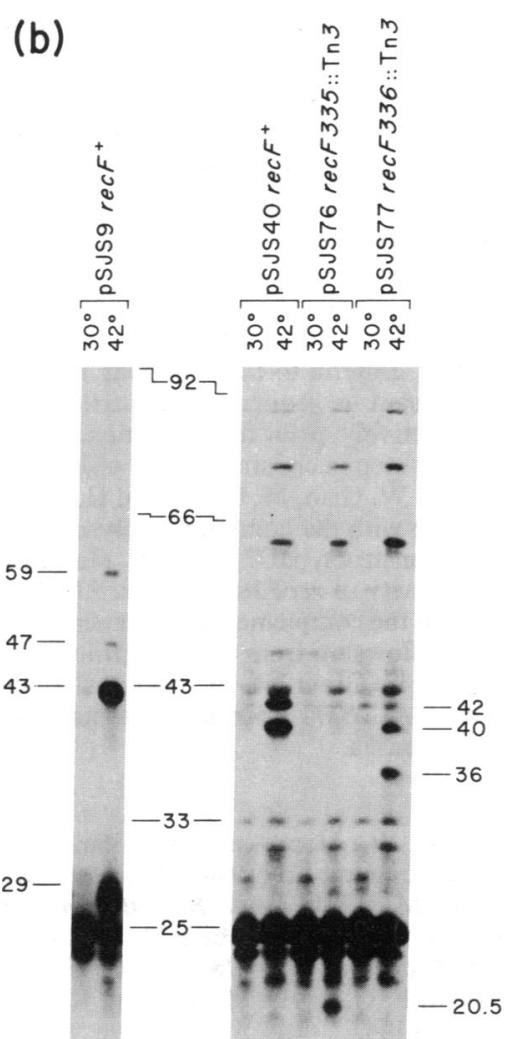

Fig. 2. (a) Features of the plasmids. The 3.6-kb $E c o R I ~ r e c F^{+}$fragment from pJC605 was cloned into a plasmid vector, constructed in this laboratory, in order to provide temperature-controlled transcription of cloned genes. pSJS 9 contains the following $\lambda$ phage genes: isodirectionally transcribing $p L$ and $p R$ promoters, the temperature-sensitive repressor $c 1857$, a doubly amber $N$ mutant $(N 3, N 57)$, and bet ${ }^{+}$. This plasmid was modified by partial digestion with Hha I to yield the plasmid pSJS40, from which $97 \%$ of $d n a N$, the remainder of $d n a A$, all of $b e t$ and part of $N$ have been deleted. In addition, two insertion mutations, recF335::Tn3 and recF336::Tn3, were substituted for recF $F^{+}$in pSJS40, yielding the $r e c F^{-}$plasmids pSJS76 and pSJS77, respectively. Portions derived from $\lambda$ phage are crosshatched. The pBEU28 vector (33) has been omitted. (b) Autoradiogram of $\left[{ }^{35}\right.$ S $]$ methionine-labeled extracts from maxicells. Protein extracts from cells containing the plasmids pSJS9, pSJS40, pSJS76, or pSJS77 were labeled at $30^{\circ} \mathrm{C}$ (noninduced) and $42^{\circ} \mathrm{C}$ (induced) and subjected to sodium dodecyl sulfate/12\% polyacrylamide gel electrophoresis in two experiments; $100,000 \mathrm{cpm}$ were loaded per lane. The gels were treated with fluor (EN ${ }^{3} \mathrm{HANCE}$, New England Nuclear) before they were dried and exposed to film for $40 \mathrm{hr}$ at $-70^{\circ} \mathrm{C}$. Molecular weight marker positions of the following marker proteins are indicated by the center numbers: phosphorylase $\mathbf{B}$, bovine serum albumin, ovalbumin, catalytic subunit of aspartate transcarbamoylase, and carbonic anhydrase. Numbers at the left and far right refer to those protein bands discussed within the text.

\section{DISCUSSION}

Almost all of the results described are consistent with the hypothesis that most of an open reading frame between $d n a N$ and $g y r B$ is $r e c F$ and that the recF gene product is a 40.5-kDa protein. The exception is our observance of $\mathrm{RecF}^{+}$ phenotype at $30^{\circ} \mathrm{C}$ (i.e., $\mathrm{UV}^{\mathrm{R}}$ ) without detecting $\mathrm{rec} F$ gene product by maxicell analysis at this temperature. At present, we think there is too little $r e c F$ gene product produced at $30^{\circ} \mathrm{C}$ to be detectable by the maxicell method. We were unable to determine the phenotype at $42^{\circ} \mathrm{C}$ because the plasmid vector we used is lethal at that temperature.

An analysis of the amino acid composition shows that the presumptive $r e c F$ gene product contains $30.3 \%$ charged amino acids and has an isoelectric point of $\approx 7.6$. A comparison of the primary structure of the $r e c F$ gene product with various DNA binding proteins has not revealed any significant similarity.

Observations have indicated that $r e c F$ and dnaN gene products are produced in substantially different amounts from a common promoter. In an earlier paper, Ream and Clark (22) were easily able to identify the $d n a N$ product in minicells but were unable to identify a $r e c F$ gene product. Other reports $(4,37)$ have identified only the dnaA and dnaN gene products from DNA of this region, although a complete recF gene was present in these studies.

There are three reasons that could explain this differential expression. First, it is possible that transcription terminates early in the recF sequence. A region of dyad symmetry begins at position 21 in Fig. 1 and ends at position 55 with a stem length of 13 nucleotide pairs and a loop distance of 9 nucleotides. This sequence may be a transcriptional pause sequence and a potential $\rho$-dependent terminator (38). Since UV irradiation suppresses polarity effects in the gal operon by reducing $\rho$ activity $(39,40)$, the amount of recF gene product might increase after irradiation without having a lexA gene product binding site nearby (unpublished results). Expression of a putative pBEU28 gene downstream from recF and detectable by its 47-kDa protein product would not be affected by such a terminator perhaps because of the intervening gyrB promoter at the carboxyl-terminal end of $r e c F(41)$. Second, it is possible that a recF transcript is cleaved by RNase action. A second region of dyad symmetry extends from position 305 through 338 (Fig. 1). The potential stem of an RNA structure from this region contains the sequence $5^{\prime}$-A-A-G-G-U-C, which is found in all symmetrical sequences of $\mathrm{T} 7$ early mRNAs cleaved by RNase III (42). Each of these two possibilities would result in truncated mRNAs, incapable of encoding a complete recF protein. Third, it is possible that translation of recF mRNA may be slow. The recF reading frame has a high percentage (43.3\%) of nonoptimal codons (43), whereas the adjacent 70 codons of the carboxyl terminus of $d n a N$ contain only $22 \%$ nonoptimal codons. All of these mechanisms may operate to prevent toxic effects due to overproduction of recF gene product. 
An interesting feature of the presented sequence is the one-base overlap of $\mathrm{recF}$ and $\mathrm{dnaN}$. Overlaps of one nucleotide are seen at the junctions of other genes in $E$. coli $(44,45)$ and have been hypothesized $(45,46)$ to couple translation of adjacent reading frames. This feature, with the neutralization of the limiting factors we have described, should allow for the overproduction and further characterization of the $r e c F$ gene product.

We are very grateful to the following people: $M$. Gellert and $\mathrm{H}$. Ohmori, who sent us sequence information on the recF and dnaN regions, respectively, prior to publication; Steven Polevoi, who performed the last step in construction of pSJS76 and pSJS77; M. Cherry, C. Gautier, W. Gish, M. Gouy, and H. Martinez for their invaluable assistance with the computer analyses; J. Nowak, for allowing us to use his construct, pJC753; and L. Margossian, who determined the UV sensitivity of $r e c F 289$ and recF332:Tn3 hemizygous strains and performed the complementation experiments. M.-E.A. was supported by a fellowship from the Fundacion Juan March. This work was supported by Grant NP-237 from the American Cancer Society and by Grant AI 05371 from the National Institute of Allergy and Infectious Diseases.

1. Ream, L. W., Margossian, L., Clark, A. J., Hansen, F. G. \& von Meyenburg, K. (1980) Mol. Gen. Genet. 180, 115-121.

2. Gellert, M. (1981) Annu. Rev. Biochem. 50, 879-910.

3. Burgers, P. M. J., Kornberg, A. \& Sakakibara, Y. (1981) Proc. Natl. Acad. Sci. USA 78, 5391-5395.

4. Hansen, F. G. \& von Meyenburg, K. (1979) Mol. Gen. Genet. 175, 135-144.

5. Fuller, R. S. \& Kornberg, A. (1983) Proc. Natl. Acad. Sci. USA 80, 5817-5821.

6. Hirota, Y., Mordoh, J. \& Jacob, F. (1970) J. Mol. Biol. 53, 369-387.

7. Horii, Z. I. \& Clark, A. J. (1973) J. Mol. Biol. 80, 327-344.

8. Rothman, R. H. \& Clark, A. J. (1977) Mol. Gen. Genet. 155, 279-286.

9. Clark, A. J., Volkert, M. R., Margossian, L. J. \& Nagaishi, H. (1982) Mutat. Res. 106, 11-26.

10. McPartland, A., Green, L. \& Echols, H. (1980) Cell 20, 731737.

11. Little, J. W. \& Mount, D. W. (1982) Cell 29, 11-22.

12. Sinden, R. R. \& Cole, R. S. (1978) J. Bacteriol. 136, 538-547.

13. Karu, A. E. \& Belk, E. D. (1982) Mol. Gen. Genet. 185, 175182.

14. Smith, C. L. (1983) Proc. Natl. Acad. Sci. USA 80, 2510-2513.

15. Witkin, E. M. (1976) Bacteriol. Rev. 40, 869-907.

16. James, A. A., Morrison, P. T. \& Kolodner, R. (1982) J. Mol. Biol. 60, 411-430.

17. Cohen, A. \& Laban, A. (1983) Mol. Gen. Genet. 189, 471-474.

18. Fishel, R. A. \& Kolodner, R. (1983) in Cellular Responses to DNA Damage, eds. Frieberg, E. C. \& Bridges, B. A. (Liss, New York), pp. 309-324.
19. Gillen, J. R., Willis, D. K. \& Clark, A. J. (1981) J. Bacteriol. 145, 521-532.

20. Armengod, M.-E. (1981) Mol. Gen. Genet. 181, 497-504.

21. Bresler, S. E., Krivonogov, S. V. \& Lanzov, V. A. (1978) Mol. Gen. Genet. 166, 337-346.

22. Ream, L. W. \& Clark, A. J. (1983) Plasmid 10, 101-110.

23. Bachmann, B. J. (1983) Microbiol. Rev. 47, 180-230.

24. Bachmann, B. J. (1972) Bacteriol. Rev. 36, 525-557.

25. Hershfield, V., Boyer, H. W. \& Yanofsky, C. (1974) Proc. Natl. Acad. Sci. USA 71, 3455-3459.

26. Uhlin, B. E., Schweickart, V. \& Clark, A. J. (1983) Gene 22, 255-265.

27. Humphreys, G. O., Willshaw, G. A. \& Anderson, E. S. (1975) Biochim. Biophys. Acta 383, 457-463.

28. Maxam, A. M. \& Gilbert, W. (1980) Methods Enzymol. 65, 499-560.

29. Sancar, A., Hack, A. M. \& Rupp, W. D. (1979) J. Bacteriol. 137, 692-693.

30. Heffron, F., McCarthy, B. J., Ohtsubo, H. \& Ohtsubo, E. (1979) Cell 18, 1153-1163.

31. Southern, E. M. (1975) J. Mol. Biol. 98, 503-517.

32. Ohmori, H., Kimura, M., Nagata, T. \& Sakakibara, Y. (1984) Gene 28, 159-170.

33. Shine, J. \& Dalgarno, L. (1974) Proc. Natl. Acad. Sci. USA 71, 1342-1346.

34. Steitz, J. A. (1979) in Ribosomes: Structure, Function, and Genetics, eds. Chambliss, G., Crowen, G. R., Davies, J., Davis, K., Kahan, L. \& Nomura, M. (Univ. Park Press, Baltimore), pp. 479-495.

35. Daniels, D. L., Schroeder, J. L., Szybalski, W., Sanger, F., Coulson, A. R., Hong, G. F., Hill, D. F., Petersen, G. B. \& Blattner, F. R. (1983) in Lambda II, eds. Hendrix, R. W., Roberts, J. W., Stahl, F. W. \& Weisberg, R. A. (Cold Spring Harbor Laboratory, Cold Spring Harbor, NY), pp. 519-684.

36. Hansen, E. B., Hansen, F. G. \& von Meyenburg, K. (1982) Nucleic Acids Res. 10, 7373-7385.

37. Yuasa, S. \& Sakakibara, Y. (1980) Mol. Gen. Genet. 180, 267273.

38. Rosenberg, M., Court, D., Shimatake, H., Brady, C. \& Wulff, D. L. (1978) Nature (London) 272, 414-423.

39. Pollock, T. J., Tessman, E. S. \& Tessman, I. (1979) J. Bacteriol. 138, 122-125.

40. Fassler, J. S. \& Tessman, I. (1980) J. Bacteriol. 144, 12051207.

41. Menzel, R. \& Gellert, M. (1984) Cold Spring Harbor Symp. Quant. Biol. 49, in press.

42. Gegenheimer, P. \& Apirion, D. (1981) Microbiol. Rev. 45, 502 541 .

43. Ikemura, T. (1981) J. Mol. Biol. 151, 389-409.

44. Yanofsky, C., Platt, T., Crawford, I. P., Nichols, B. P., Christie, G. E., Horowitz, H., van Cleemput, M. \& Wu, A. M. (1981) Nucleic Acids Res. 9, 6647-6668.

45. Schumperli, D., McKenney, K., Sobieski, D. A. \& Rosenberg, M. (1982) Cell 30, 865-871.

46. Oppenheim, D. S. \& Yanofsky, C. (1980) Genetics 95, 785795. 